(c) American Dairy Science Association, 2004.

\title{
Technical Note: A Computerized System for Monitoring Feeding Behavior and Individual Feed Intake of Dairy Cattle
}

\author{
A. Bach, ${ }^{1,2}$ C. Iglesias, ${ }^{2}$ and I. Busto ${ }^{3}$ \\ ${ }^{1}$ Institució Catalana de Recerca i Estudis Avançats (ICREA), \\ 08010 Barcelona, Spain \\ ${ }^{2}$ Institut de Recerca i Tecnología Agroalimentàries, \\ IRTA-Unitat de Remugants, 08193 Barcelona, Spain \\ ${ }^{3}$ Diputació de Girona-SEMEGA, 17003 Girona, Spain
}

the total amount of feed consumed daily by each animal, and the rate at which animals consume feed.

(Key words: feeding behavior, dairy cow, monitorization)

Traditionally, feeding behavior of loose-housed cows has been monitored through direct human observation or using time-lapse video recording systems (Friend et al., 1977; Vasilatos and Wangsness, 1980). Both of these systems are labor intensive, which limits their use for long periods of time. Recently, Tolkamp et al. (2000) described an individual intake monitoring system that collected continuous feeding behavior data for loosehoused cows. However, cows using this system were required to access the feed via an electronic gate, potentially affecting feeding behavior compared with that in regular loose-housed systems. More recently, DeVries et al. (2003) validated the use in dairy cattle of a previously described system (Sowell et al., 1998; SchwartzkopfGenswein et al., 1999) used to monitor beef feeding behavior. This system allowed for the monitorization of the presence of a given cow in the feed alley with a minimum time interval of $6 \mathrm{~s}$; however, feed intake was not measured. The objective of the current study was to develop and validate a system that allows for the study of feeding behavior plus feed intake of loose-housed dairy cattle without any restriction on access to the feedbunk.

A total of 28 scales $(65 \times 90 \mathrm{~cm})$ were installed in front of each feeding place of an entire regular feedbunk (20.5 m) with 28 feeding self-locking places. Each scale (DI160; Merican, Barcelona, Spain) had a load cell able to resist $300 \mathrm{~kg}$ of weight. The scales had a weighing capacity of $100 \mathrm{~kg}$ with an accuracy of $\pm 20 \mathrm{~g}$. Each scale was equipped with a 200-L fiberglass box to accommodate the daily TMR. Each visit to the feedbunk was monitored by a transponder (Unic; Circontrol, Barcelona, Spain) in the right ear of each cow that was detected by a proximity reader (CP-15; Circontrol) located at the top right corner of each headlock. This location allowed for the detection of the time at which a cow was entering and exiting the feedbunk, but would provide no signal when the cow's
Received April 30, 2004.

Accepted August 12, 2004.

Corresponding author: A. Bach; e-mail: alex.bach@irta.es. 

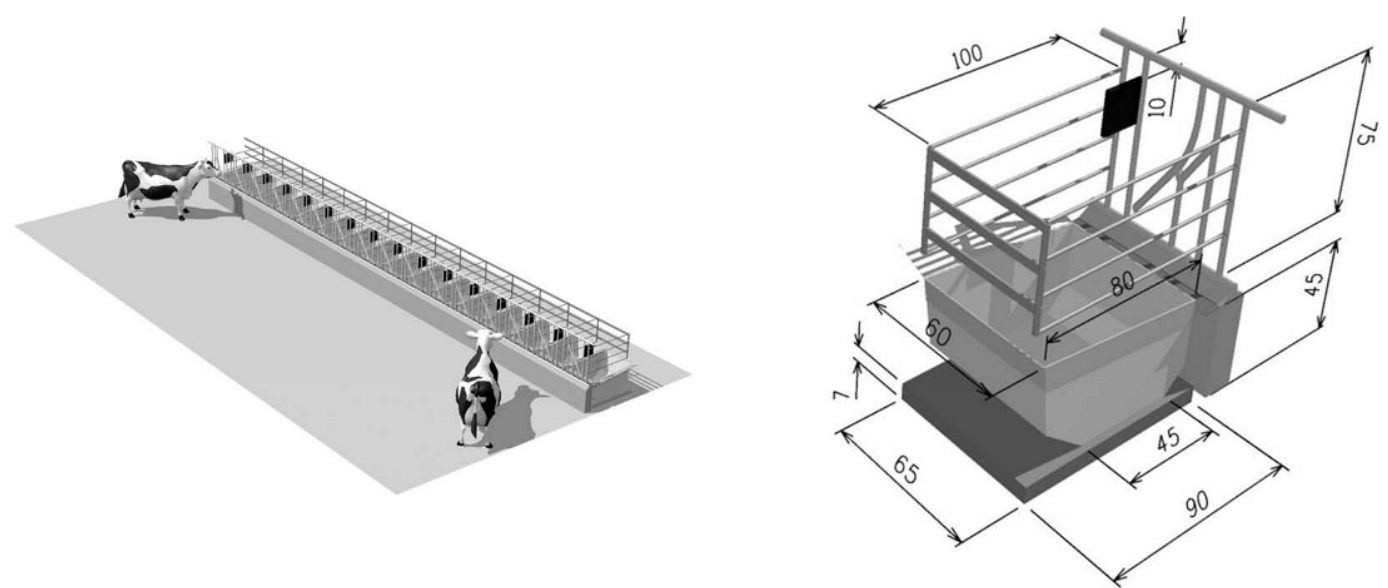

Figure 1. Scheme of the location and dimensions $(\mathrm{cm})$ of each scale and proximity reader.

head was down eating. The CP-15 proximity reader was able to detect the magnetized transponder at a maximum distance of $15 \mathrm{~cm}$. To prevent cows from eating from their neighboring scales, each scale was individualized by mobile iron bars that would fold at the time of offering the TMR. Figure 1 illustrates the arrangement of the scales, proximity readers, fiberglass boxes, and feed separation bars. The RS-232C signal from each scale and the RS-485 signal from each proximity reader were converted into an ethernet signal using an NportServer (Moxa Technologies Co. Ltd., Taipei, Taiwan). The ethernet signal from each scale was then sent to a computer that recorded all data. All digital displays of each scale, plus the signal converters, were installed inside a thermoplastic distribution assembly box equipped with forced ventilation to dissipate the heat produced by the electronic equipment. All data were processed using LabView (National Instruments, Austin, TX). The average time needed to complete an entire round of data collection from each scale and proximity reader was about $3.5 \mathrm{~s}$.

The monitoring system was validated using the 28 feeding places and 51 lactating cows. Cows were kept in the research facility of IRTA-Unitat de Remugants, located in Girona, Spain, and were managed under the supervision and guidelines of the Animal Care Committee of IRTA. Cows were fed a TMR (15.4\% CP, 33.5\% $\mathrm{NDF}, 1.49 \mathrm{Mcal} \mathrm{NE}_{\mathrm{L}} / \mathrm{kg}$ on a DM basis) once daily at the feed alley (with the scales), plus between 1.5 and $3 \mathrm{~kg} /$ $\mathrm{d}$ (depending on milk production and stage of lactation) of concentrate $\left(19.6 \% \mathrm{CP}, 2.02 \mathrm{Mcal} \mathrm{NE}_{\mathrm{I}} / \mathrm{kg}\right.$ on a DM basis) offered by an automated milking system (VMS, DeLaval, Sweden) during milking.

The validation of the monitoring system was conducted in a series of 4 -h observations during $5 \mathrm{~d}$. During these observation periods, 2 observers recorded the cow number and the time of the visit to each scale. Each observer was responsible for observing 14 scales. Each person used a digital timer synchronized with the time of the computer. To validate the ability of the system to monitor feed intake, on $3 \mathrm{~d}$, the feed in 18 scales was removed and weighed in an external scale at the beginning and at the end of $26 \mathrm{cow}$ visits. The estimated feed consumption by the monitoring system was then compared with the consumption estimated manually (initial weight minus final weight determined with an external scale). Also, on 2 different d, the total feed that had disappeared from each scale during a period of 24 $\mathrm{h}$ was compared with the sum of feed disappearances recorded by the monitoring system at each cow visit. The records obtained by direct observations were then compared with the data recorded by the computer using an ANOVA with the following linear model:

$$
\mathrm{Y}_{\mathrm{ij}}=\mu+\operatorname{Method}_{\mathrm{i}}+\operatorname{Day}_{\mathrm{j}}+\operatorname{Method}_{\mathrm{i}} \times \operatorname{Day}_{\mathrm{j}}+\varepsilon_{\mathrm{ij}},
$$

where Y represents the time of entrance to or exit from the feedbunk, Method refers to direct vs. automatic observations, and Day represents the day of observation. All statistical analyses were conducted with JMP (2002; version 5.0.1 for Macintosh, Cary, NC). Meal durations and feed consumptions calculated from direct observations were compared with the meal durations and feed consumptions obtained from the monitoring system using linear regression analysis (direct observations were considered the independent variable and automatic observations the dependent variable).

A similar system has been described by DeVries et al. (2003); however, their system recorded only cow presence in the feedbunk, whereas the system described herein, in addition to allowing for the monitoring of both cow presence and exact position of the cow in the feed- 
bunk, also allows for the measurement of the amount of feed consumed by each cow every time a cow eats. The computer system was more efficient than the human observers in terms of detecting cow presence at the manger. During the 5 observational periods, a total of 1583 visits were detected by the monitoring system, whereas 1468 visits were detected by human observers. The computer detected 115 more visits than the human observers, but for a total of 96 occasions of the 115 where the presence of a cow failed to be detected by the human observers, the cow presence was confirmed by a change in feed weight at the scale, implying that the failure was at the human side rather than in the monitoring system. However, there were 19 occasions that could not be confirmed because the weight of the scales remained unchanged. Therefore, there were 19 occasions where cows should have been considered absent by the system but were recorded as present. This represented a $98.8 \%$ potential specificity $(19 / 1583$; likelihood that a cow that is absent from the feedbunk is recorded as absent by the computer) of the monitoring system. This value represents potential specificity because the 19 cases that were not detected by human observers could have been due to human errors rather than errors associated with the monitoring system. In any case, this potential specificity is a conservative value limited by the shortcomings of direct human observations. Conversely, there were 6 occasions in which a cow presence was detected by the human observers, but the computer failed to record it. This represents a sensitivity of $99.6 \%$ (6/1583; probability that a cow actually present at the feeder is detected as present by the computer). DeVries et al. (2003) reported a specificity and sensitivity of 99.2 and $87 \%$, respectively; thus, it can be concluded that the system described herein is equally specific but more sensitive than those formerly described.

Cows visited the feedbunk a total of 46 times in $24 \mathrm{~h}$, but several of these visits were part of the same meal. Meal duration was not calculated, as it was beyond the scope of this study. The average time spent in a given scale by each cow obtained by direct observation was 5 min and $45 \pm 10 \mathrm{~s}$, whereas it was $5 \mathrm{~min}$ and $52 \pm 10 \mathrm{~s}$ when estimated automatically with the monitoring system. Although it might seem that the monitoring system could overestimate the permanence time in the feedbunk, the difference of $7 \mathrm{~s}$ was not significant $(P=0.60)$, and the slope of the regression line between visit length estimated by the monitoring system and by human observers was not significantly different $(P=0.87)$ from 1 .

The difference between the feed consumed by a cow during a visit differed only in $52 \mathrm{~g}(P=0.99)$ when comparing the values obtained with the monitoring system $(3.97 \pm 0.68 \mathrm{~kg})$ with the manual $(3.91 \pm 0.69 \mathrm{~kg})$ weights before and after each cow visit. Also, the comparison of the total feed that disappeared in $24 \mathrm{~h}$ from each scale in 2 separate $d$ with the sum of the feed consumed by each cow during this period numerically $(P=0.95)$ differed by $120 \mathrm{~g}(20.90 \pm 1.33 \mathrm{vs} .20 .78 \pm 1.32 \mathrm{~kg}$, respectively), indicating that the monitoring system was sufficiently accurate in the measure of feed consumption. The numerically greater feed intake value obtained with the monitoring system could be partially attributed to the loss of moisture during the 24-h observation periods.

In conclusion, the described system proved to be a useful tool to provide reasonable estimates of the number of visits per animal, length of each visit, amount of feed consumed per visit and animal, total amount of feed consumed daily by each animal, and rate at which animals consume feed, allowing the study of feeding behavior and the monitoring of individual feed intake and eating patterns of group-housed cows.

\section{ACKNOWLEDGMENTS}

The authors are grateful to Departament d'Universitats, Recerca i Societat de la Informació (DURSI) and Instituto nacional de Investigación y Tecnología Agraria y Alimentaria (INIA) for their essential and important financial contributions to this project. Also, the authors send a special thanks to Xavier Carré for his unconditional support, and to the barn crew, Carolina, Salvador, and Lluis, for their assistance and patience during the installation of the equipment. Thanks as well to Maria Devant and Marta Terré for their scientific support and assistance with the assembling of the equipment.

\section{REFERENCES}

DeVries, T. J., M. A. G. von Keyserlingk, D. M. Weary, and K. A. Beauchemin. 2003. Technical note: Validation of a system for monitoring feeding behavior of dairy cows. J. Dairy Sci. 86:3571-3574.

Friend, T. H., C. E. Polan, and M. L. McGilliard. 1977. Free stall and feed bunk requirements relative to behavior, production and individual feed intake in dairy cows. J. Dairy Sci. 60:108-116.

JMP. 2002. JMP The Statistics Discovery Software. SAS Inst., Inc., Cary, NC.

Schwartzkopf-Genswein, K. S., C. Huisma, and T. A. McAllister. 1999. Validation of a radio frequency identification system for monitoring the feeding patterns of feedlot cattle. Livest. Prod. Sci. 60:27-31.

Sowell, B. F., J. P. G. Bowman, M. E. Branine, and M. E. Hubbert. 1998. Radio frequency technology to measure feeding behavior and health of feedlot steers. Appl. Anim. Behav. 59:277-284.

Tolkamp, B. J., D. P. N. Schweitzer, and I. Kyriazakis. 2000. The biologically relevant unit for the analysis of short-term feeding behavior of dairy cows. J. Dairy Sci. 83:2057-2068.

Vasilatos, R., and P. J. Wangsness. 1980. Feeding behavior of lactating dairy cows as measured by time-lapse photography. J. Dairy Sci. 63:412-416. 